\title{
REDUCING DELAY IN HEALTHCARE DELIVERY AT OUTPATIENTS CLINICS USING DISCRETE EVENT SIMULATION
}

\author{
Al-Araidah, O. ; Boran, A.** \& Wahsheh, A.* \\ * Industrial Engineering Department, Jordan University of Science and Technology, \\ Irbid, 22110, Jordan \\ ${ }^{* *}$ Public Health Department, Jordan University of Science and Technology, Irbid, 22110, Jordan \\ E-mail: alarao@just.edu.jo,boran@just.edu.jo, aawahsha08@eng.just.edu.jo
}

\begin{abstract}
Outpatient clinics are demanding more consideration to enhance their performance and quality of care. This paper presents a thorough exploration of the outpatient clinics' environment at a local hospital. The ophthalmology outpatient clinic was selected for a case study. To this end, the total visit time and service times at stations were collected and fed into a Discrete Event Simulation (DES) model. The model was validated through a statistical comparison with the performance of the real system. Various improvement alternatives were then proposed and investigated using the DES model. Key performance indicators of the system, including expected waiting time and expected visit length, were traced. Findings indicated that many improvement scenarios could be applied with significant amounts of reduction in waiting time up to $29 \%$ and visit length up to $19 \%$ without investing in new resources.

(Received in November 2011, accepted in April 2012. This paper was with the authors 1 month for 2 revisions.)
\end{abstract}

Key Words: Healthcare, Discrete Event Simulation, Quality, Ophthalmology

\section{INTRODUCTION}

Healthcare services, like many other services, experience an increasing pressure to advance the level of quality provided to patients [1]. Key care dimensions, as judged by patients, include accessibility, timeliness and effectiveness of care [2]. Unlike inpatient clinics, outpatient clinics are characterized by rapid growth, variability, uncertainty in demand, and fast daily pace [3]. Such characteristics necessitate efforts to explore improvement opportunities at these clinics [4]. Today, waste reduction lean principles have been successfully applied in the healthcare environment enabling hospitals and clinics to enhance their performance and quality as perceived by their patients $[5,6]$. In healthcare, lean thinking contributed to the performance improving of processes by smoothing patient flow, utilizing resources effectively and determining operational decision-making choices [7].

Many researchers used lean philosophies and tools to run successful projects in healthcare organizations. An inpatient pharmacy at a local Jordanian hospital achieved a reduction in lead time by utilizing lean concepts [8]. The authors reported savings of more than $45 \%$ in the drug dispensing cycle time. Bolton Hospital blood labs successfully eliminated 57 steps from the routine blood sample's journey through workplace redesign and process simplification [9]. Many studies used Discrete Event Simulation (DES) to model, analyse and improve the manufacturing sector. In [10], the authors used DES to model a flow line where production speed of a machine is regulated by the length of queue. The authors studied the impact of the several production parameters on the performance of the system and used the simulation package to optimize the system under the predefined conditions. In [11], the 
authors presented a general DES model for an unreliable and an unbalanced transfer line with no intermediate buffers. Statistical investigations show that the outputs of the DES model were significantly different from those obtained using approximation techniques from the literature. In [12], the authors used DES to test the relative advantages of process and cellular layouts under various production factors and strategies. Results obtained from the study show that a layout alternative may lose its advantage when considering part routing, and queuing and job overlapping strategies. In [13], the authors illustrated the impact of the poor choice of failure parameters and distributions on the outputs of DES models of a production line. Moreover, the authors showed that placing unreliable machines towards the end of the production line can improve the throughput of the line.

In the healthcare sector, DES was used in [14] to model and investigate possible improvements at the radiation therapy facility at British Columbia Cancer Agency. The model reduced planning time by more than $20 \%$ and resulted in a scenario that reduced the length and variability of oncologist delays. In [15], the researchers evaluated the impact of different appointment and patient-doctor allocation strategies on the cycle time of patients clinical visits, Based on simulation model projections, it was found that the appointment system reduced the median and the $95^{\text {th }}$ percentile cycle times for appointment patients, where the walk in allocations did not provide effective contribution to the overall cycle time reduction. In [16], the authors used DES and six-sigma to enhance the performance at the emergency department (ED) of a Jordanian hospital. The authors suggested and tested a triage process and reported $34 \%$ reduction in Length of Stay (LOS) and $61 \%$ reduction in patients waiting time. In [17], a regional Australian emergency department used DES to evaluate the impact of various staffing levels on service efficiency. The model helped department management determine the optimal number of medical personnel required to maximize patient throughput.

This paper investigates patients' flow in an ophthalmology outpatient clinic of a local hospital. The study aimed at identifying and eliminating root causes behind the long waiting times and the long total visit times of concern to patients. Information about the work procedures and problems at the ophthalmology clinic were obtained through interviews with medical personnel and patients, and were validated against survey results at the quality department. Processes and work procedures in the clinic were defined and service times were measured and analysed. The processes at the clinic were then modelled and validated using an Arena DES Software. Several improvement scenarios were suggested and tested using the model and potential savings are reported. The proposed scenarios took into account arrival patterns of patients and scheduling practices used at the clinic. The work was locally supervised by the head nurse, resident doctor and the quality supervisor.

The rest of the paper is organized as follows. The next section provides an overview of operations at the clinic. Section three discusses the DES model. Section four presents improvement scenarios and results. The final section provides concluding remarks.

\section{OVERVIEW}

Outpatient clinics are medical facilities that provide healthcare to non-hospitalized patients. Patients visit the clinic on daily basis for consultation, diagnosis, treatment and follow up treatment [18]. In this study, outpatient clinics are located in the hospital campus, have similar layouts, and have the same work policies. Clinics work two shifts namely 8:00am to 12:00pm and $1: 00 \mathrm{pm}$ to $5: 00 \mathrm{pm}$. The investigated ophthalmology clinic has four examination rooms and is staffed by one clerk, one medical record receptionist, three nurses, three resident doctors and one specialist doctor. The clinic operates three days a week and serves an average of 64 patients per day. Other weekly work days are dedicated for tests and examinations provided by technicians. The Pareto chart, illustrated in Fig. 1, shows categories of patients' 
complaints according to a survey by the hospital quality department. Among the many, long waiting times, congestions and incomplete treatments are the most reported deficiencies.

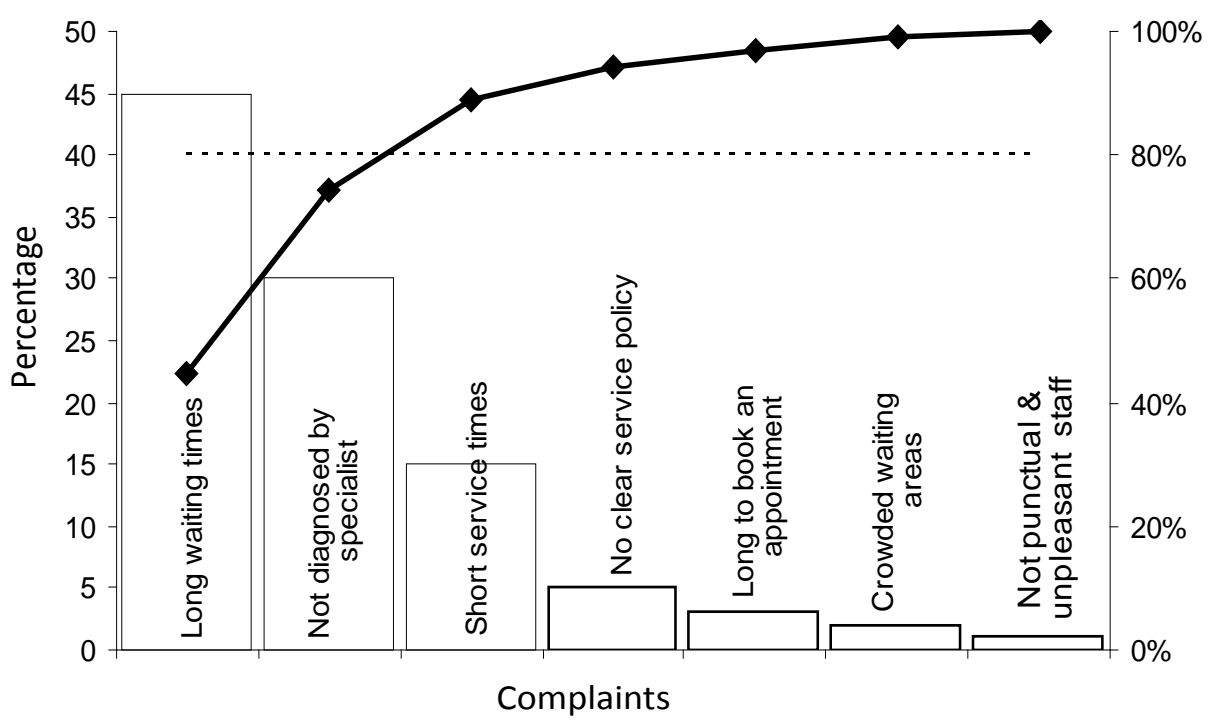

Figure 1: Patients complaints at outpatient clinics.

Fig. 2 shows the process map configuration and the patient flow during a typical visit to the ophthalmology outpatient clinic. Patients arriving at the clerk station are classified into patients with pre-booked appointments and walk-in patients. The clerk is authorized to accept around $5 \%$ of the total clinic capacity as walk-ins on a first come first served base. After registration at the clerk, the patient arrives at the medical record (MR) receptionist to provide personal and visit information to be documented into the patient's MR file. The MR files of booked patients should be ready at this station prior to shift time. MR files are ordered from the MR department in variable size batches based on patients' arrival rate. The clinical diagnosis starts at the nurse station with routine tests and examinations. In addition, nurses are tasked to instruct patients on treatment options and risks, discuss any related medical history, and accompany the patient to the Resident Dr. station (the treatment room), where intensive diagnosis begins. If tests are needed, the patient leaves the treatment room either to the nurse station in a second contact for tests at the clinic or to radiology or laboratories within the hospital campus for an out of clinic test. If test results are obtained during the same work day, the patient returns to Resident Dr. station at the ophthalmology clinic to continue the care journey. Otherwise, the patient is dispensed and is rescheduled for a next appointment. Following the evaluation/treatment by the resident doctor, the patient is either discharged or is diverged to the Specialist Dr. station.

\section{THE DES CLINIC MODEL}

The flow of patients between stations, as described in the previous section, is simulated using Rockwell Arena DES software [19] and [20]. The DES model aims at understanding the performance of the current state of the clinic and to investigate potential improvement scenarios [21]. Therefore, data and information concerning patient arrival pattern and service times at each station were collected and validated.

Patient arrival pattern reflects the commuting of patients to stations in the system [22]. In outpatient clinics, the pattern is fairly predictable and follows a clear path as illustrated in Fig. 2. However, it is observed that patients tend to arrive up to two hours earlier than the time of the appointment. Fig. 3 shows a 5 weeks average of patient arrival rates clerk station over a 
work day expressed in number of patients attend per a 15 minutes period. The figure shows that patients cluster at the beginning of each shift that is patients are more likely to attend early. Patients keep flowing to the clinic during the break time. Moreover, patients rarely attend after 3:00 pm.

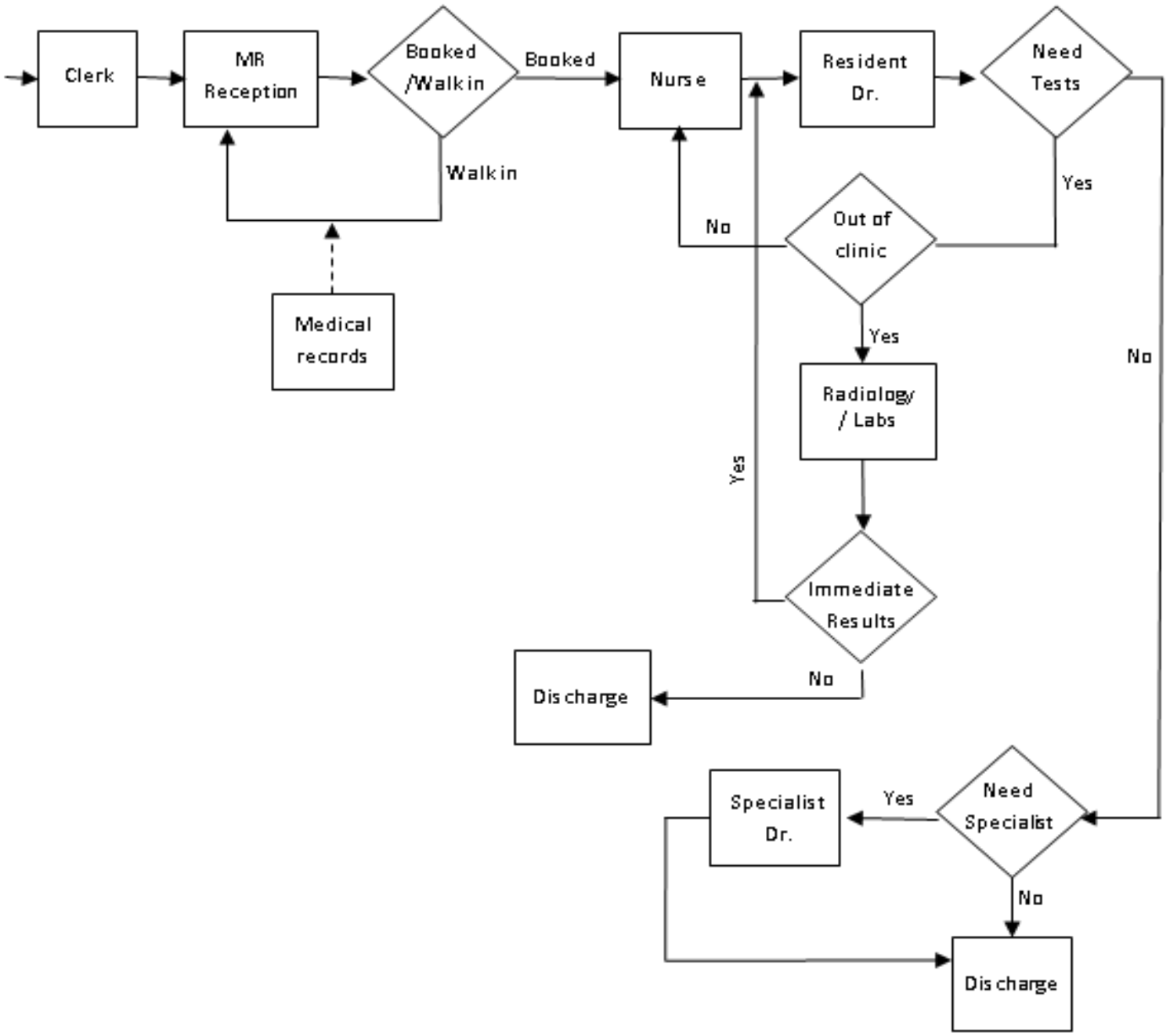

Figure 2: Process Map for the Ophthalmology Outpatient Clinic.

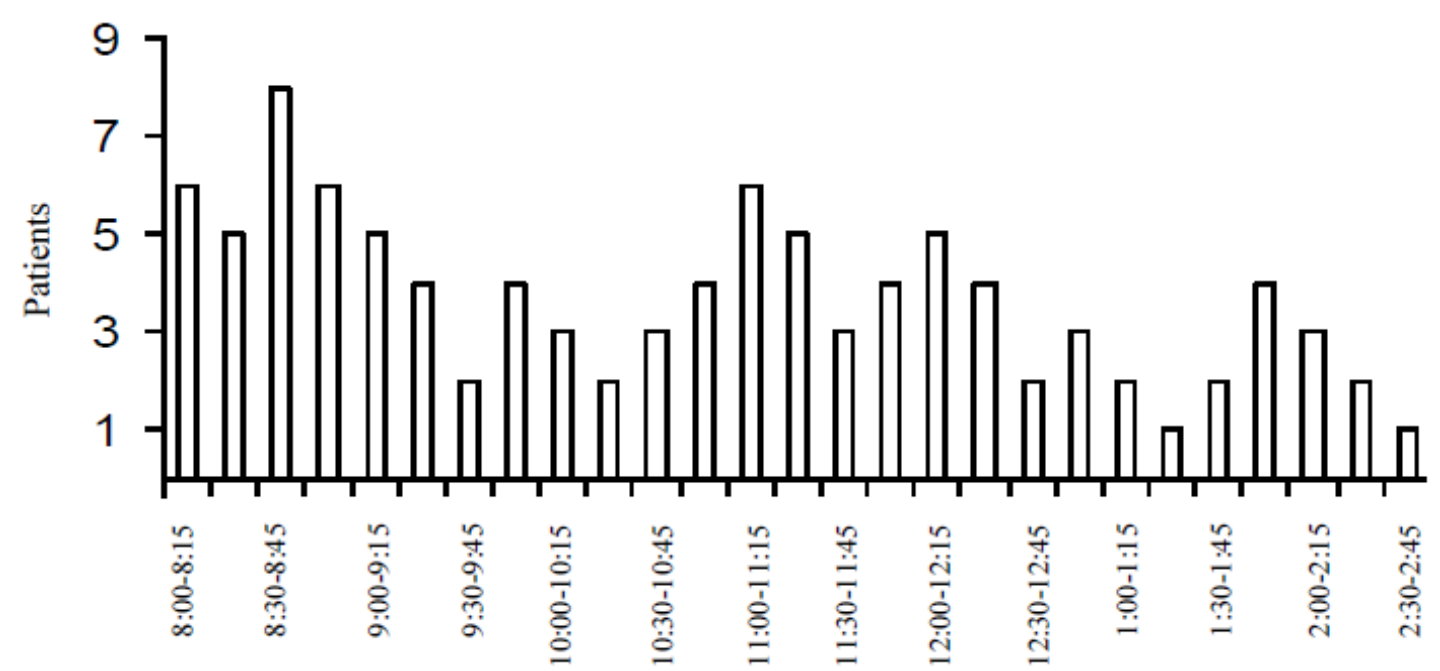

Figure 3: Patients arrival rate per 15 minutes period (from 8:00 am to 2:45 pm). 
A time study was conducted to measure the service time at each station and the total visit time (the time elapses patient's arrival and departure) for samples of patients. Table I and Table II present samples of collected data. Using Arena input analyser, service times are analysed and the best fit distributions are indicated as illustrated in Table III. For a 0.05 type I error ( $\alpha$ - error), the Specialist doctor station's service distribution is rejected as $p<\alpha$ [23]. Therefore, an empirical discrete fit for the Specialist Dr. station is used instead. Clinic staff estimated that ordering and preparing medical records for walk-in patients take about 30 minutes. Moreover, they estimated that radiology or a laboratory test would take 20 minutes on average. From Table I and Fig. 2, a patient is expected to spend around 73.2 minutes in the clinic if she/he visits all stations. On the other hand, Table II shows that a patient spends about 140 minutes on average in the clinic. This indicates that patients spend long times waiting for services at the stations.

Table I: Sample service times (minutes) at each station.

\begin{tabular}{|c|c|c|c|c|c|c|c|}
\hline Sample \# & Clerk & $\begin{array}{c}\text { MR } \\
\text { Reception }\end{array}$ & $\begin{array}{c}\text { Nurse } 1^{\text {st }} \\
\text { contact }\end{array}$ & $\begin{array}{c}\text { Res. Dr. } \\
\mathbf{1}^{\text {st }} \text { contact }\end{array}$ & $\begin{array}{c}\text { Nurse } 2^{\text {nd }} \\
\text { contact }\end{array}$ & $\begin{array}{c}\text { Res. Dr. } 2^{\text {nd }} \\
\text { contact }\end{array}$ & $\begin{array}{c}\text { Specialist } \\
\text { Dr. }\end{array}$ \\
\hline 1 & 4 & 5 & 16 & 26 & 5 & 20 & 12 \\
\hline 2 & 3 & 7 & 8 & 30 & 3 & 16 & 8 \\
\hline 3 & 5 & 5 & 8 & 25 & 4 & 14 & 10 \\
\hline 4 & 4 & 5 & 5 & 22 & 7 & 30 & 16 \\
\hline 5 & 2 & 6 & 12 & 18 & 5 & 25 & 13 \\
\hline 6 & 3 & 3 & 10 & 32 & 6 & 20 & 7 \\
\hline 7 & 4 & 6 & 3 & 19 & 4 & 12 & 19 \\
\hline 8 & 5 & 4 & 7 & 17 & 6 & 15 & 5 \\
\hline 9 & 2 & 5 & 10 & 28 & 5 & 18 & 15 \\
\hline 10 & 2 & 6 & 3 & 20 & 4 & 14 & 8 \\
\hline 11 & 4 & 3 & 11 & 30 & 4 & 22 & 7 \\
\hline 12 & 4 & 6 & 6 & 28 & 7 & 15 & 10 \\
\hline 13 & 3 & 5 & 5 & 22 & 5 & 17 & 12 \\
\hline 14 & 3 & 7 & 14 & 32 & 6 & 15 & 8 \\
\hline 15 & 4 & 3 & 8 & 18 & 6 & 20 & 14 \\
\hline 16 & 2 & 5 & 8 & 23 & 8 & 15 & 13 \\
\hline 17 & 4 & 4 & 4 & 17 & 3 & 17 & 12 \\
\hline 18 & 3 & 5 & 13 & 32 & 4 & 13 & 8 \\
\hline 19 & 5 & 6 & 7 & 20 & 6 & 12 & 7 \\
\hline 20 & 4 & 5 & 10 & 24 & 7 & 17 & 12 \\
\hline 21 & 2 & 4 & 5 & 19 & 4 & 11 & 6 \\
\hline 22 & 5 & 4 & 10 & 18 & 5 & 19 & 10 \\
\hline 23 & 5 & 6 & 12 & 23 & 6 & 23 & 12 \\
\hline 24 & 5 & 4 & 13 & 27 & 8 & 15 & 14 \\
\hline 25 & 3 & 5 & 9 & 21 & 4 & 16 & 15 \\
\hline 26 & 6 & 5 & 9 & 15 & 3 & 14 & 9 \\
\hline 27 & 4 & 6 & 2 & 18 & 4 & 20 & 8 \\
\hline 28 & 2 & 7 & 6 & 22 & 4 & 29 & 12 \\
\hline 29 & 4 & 4 & 5 & 15 & 6 & 25 & 8 \\
\hline 30 & 3 & 6 & 7 & 17 & 5 & 17 & 11 \\
\hline Mean & 3.63 & 5.07 & 8.20 & 22.60 & 5.13 & 17.87 & 10.70 \\
\hline St. Dev. & 1.13 & 1.14 & 3.51 & 5.28 & 1.41 & 4.81 & 3.32 \\
\hline
\end{tabular}


Table II: Sample of patients visit times (hours).

\begin{tabular}{|c|c|c|c|}
\hline Sample \# & Attendance at & Departure at & Visit time (hours) \\
\hline 1 & 09:15 & 01:00 & 3.85 \\
\hline 2 & $12: 10$ & $02: 15$ & 2.05 \\
\hline 3 & $01: 00$ & 03:40 & 2.40 \\
\hline 4 & $07: 43$ & $11: 26$ & 3.43 \\
\hline 5 & 09:48 & $11: 15$ & 1.27 \\
\hline 6 & $08: 20$ & 01:05 & 4.45 \\
\hline 7 & $02: 22$ & $05: 32$ & 3.10 \\
\hline 8 & 02:35 & $04: 50$ & 2.15 \\
\hline 9 & 08:04 & $11: 36$ & 3.32 \\
\hline 10 & $02: 30$ & $03: 50$ & 1.20 \\
\hline 11 & $07: 50$ & $09: 45$ & 1.55 \\
\hline 12 & $09: 43$ & $11: 25$ & 1.42 \\
\hline 13 & $10: 13$ & $11: 30$ & 1.17 \\
\hline 14 & $09: 40$ & $01: 00$ & 3.20 \\
\hline 15 & $12: 20$ & 03:45 & 3.25 \\
\hline 16 & 08:00 & $10: 15$ & 2.15 \\
\hline 17 & $10: 25$ & $01: 00$ & 2.35 \\
\hline 18 & $01: 00$ & $03: 20$ & 2.20 \\
\hline 19 & $02: 00$ & 04:00 & 2.00 \\
\hline 20 & 09:15 & $11: 45$ & 2.30 \\
\hline 21 & $10: 00$ & $01: 15$ & 3.15 \\
\hline 22 & 01:33 & $03: 20$ & 1.47 \\
\hline 23 & $11: 10$ & 02:05 & 2.55 \\
\hline 24 & $12: 15$ & $02: 20$ & 2.05 \\
\hline 25 & $08: 10$ & $11: 16$ & 3.06 \\
\hline 26 & $08: 27$ & $11: 50$ & 3.23 \\
\hline 27 & $10: 45$ & 01:05 & 2.60 \\
\hline 28 & $01: 10$ & $03: 25$ & 2.15 \\
\hline 29 & $07: 55$ & $10: 30$ & 2.35 \\
\hline 30 & 08:10 & $11: 15$ & 3.05 \\
\hline \multicolumn{3}{|r|}{ Mean } & 2.33 \\
\hline \multicolumn{3}{|r|}{ St. Dev. } & 0.99 \\
\hline
\end{tabular}

Figure 4 illustrates the Arena simulation model used in the study. To analyse the current state and to validate the model, 30 runs of 9 hours long each (a replication represents one work day) resulted in an average waiting time of 107.92 minutes and an average total visit time of 160.31 minutes for scheduled patients. Table IV presents queuing times and average number of patients in queue at each station. Results show that the longest time a patient spends waiting is at the queue of Resident Dr. station indicating that it is the bottleneck station, not the specialist doctor as most of patients and clinic staff think. Results are validated by conducting Student's $t$-test, with $\alpha=0.05$, on total waiting time. A result of $p$-value $=0.22$ failed to reject the null hypothesis that assumes no difference between the model and the actual clinic performance. 
Table III: Statistics of clinical data of service times (minutes) for stations.

\begin{tabular}{|c|c|c|c|c|c|}
\hline Station & $\boldsymbol{N}$ & Mean & St. Dev. & Distribution & $\boldsymbol{p}$-value \\
\hline Clerk & 48 & 3.58 & 1.11 & $1.5+5 * \operatorname{BETA}(1.66,2.32)$ & 0.604 \\
\hline MR receptionist & 48 & 3.86 & 1.17 & $1.5+5 * \operatorname{BETA}(1.66,1.85)$ & 0.254 \\
\hline Nurse: $1^{\text {st }}$ contact & 48 & 8.19 & 3.33 & $\operatorname{NORM}(8.19,3.33)$ & 0.462 \\
\cline { 2 - 6 } $2^{\text {nd }}$ contact & 30 & 5.19 & 1.40 & $\operatorname{TRIA}(2.5,4,8.5)$ & 0.346 \\
\hline Res. Dr.: $1^{\text {st }}$ contact & 48 & 22.64 & 5.46 & $12.5+\operatorname{ERLA}(3.37,3)$ & 0.627 \\
\cline { 2 - 6 } $2^{\text {nd }}$ contact & 30 & 17.94 & 4.87 & $\operatorname{POIS}(15.4)$ & 0.397 \\
\hline Spec. Dr. & 30 & 10.79 & 3.40 & $4.5+15 * \operatorname{BETA}(1.56,2.17)$ & $\mathbf{0 . 0 4 7 9}$ \\
\hline
\end{tabular}
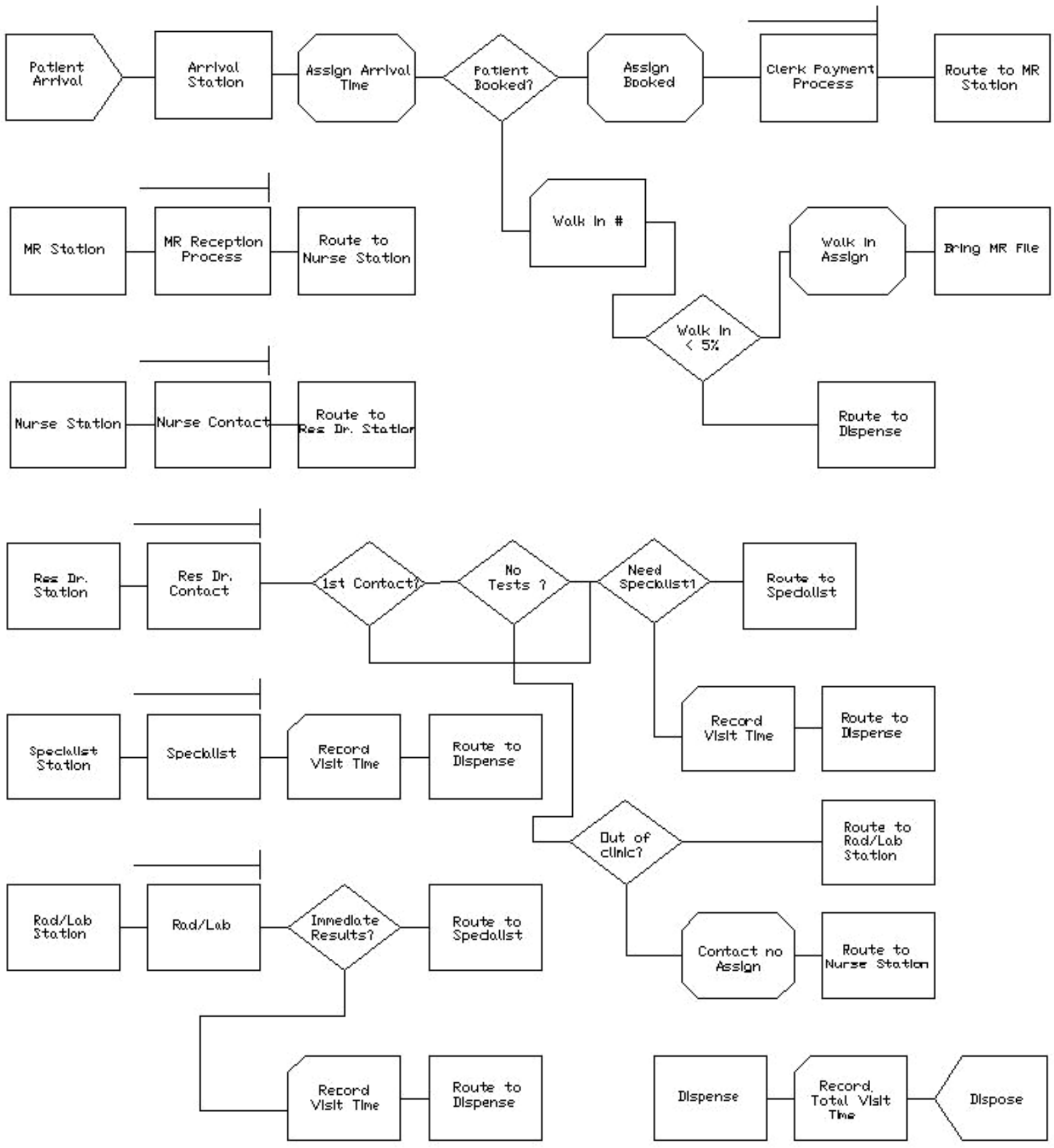

Figure 4: Arena simulation model of the ophthalmology outpatient clinic. 
Table IV: Current state analysis: Expected waiting time in queue (minutes); Expected number of patients waiting in queue; and Utilization.

\begin{tabular}{|l|c|c|c|}
\hline Station & Waiting time & Number waiting & Utilization \\
\hline Clerk & $22.73 \pm 3.15$ & 2.66 & 0.40 \\
\hline MR reception & $6.10 \pm 1.12$ & 0.70 & 0.44 \\
\hline Nurse & $0.82 \pm 0.23$ & 0.10 & 0.33 \\
\hline Resident Dr. & $77.98 \pm 12.97$ & 10.90 & 0.79 \\
\hline Specialist Dr. & $9.49 \pm 1.60$ & 0.42 & 0.49 \\
\hline
\end{tabular}

\section{IMPROVEMENT SCENARIOS AND RESULTS}

This section presents four improvement scenarios of which only one scenario requires investment in capacity building namely expanding the bottleneck station by adding a resident doctor.

Scenario 1: Controlling Arrival Patterns

In this scenario, we base our improvement proposal on the arrival behaviour of patients. It is noticed that each patient hasten to get serviced earlier than others believing that the clinic's service policy is First in First out (FIFO). This explains the clusters of patients at the early beginning of work shifts that result in congestions in the clinic. Therefore, we propose that a patient is allowed to register and pay at the clerk station no more than 30 minutes prior to her/his appointment time emphasizing that the service policy upon scheduled appointments is not FIFO except for walk-ins patients.

Scenario 2: Rescheduled resources

In this scenario, we propose that a limited capacity of the medical staff operate during the break hour between the two shifts. In other words, not all nurses and doctors take their break at the same time. To this end, we propose that two nurses and two resident doctors have their break times from 1:00 pm to 2:00 pm instead of 12:00 pm to 1:00 pm. The schedules would be cyclical among staff members to balance the slight differences in their utilizations.

Scenario 3: Combining scenarios 1 and 2

This scenario aims at combining the advantages of regulating the arrival pattern and that of rescheduling resources.

Scenario 4: Capacity building

In this scenario, the capacity of the bottleneck station is increased by hiring an additional resident doctor. Although this solution increases costs and is not applicable due to the clinic's facility limitations, it can be tested and simulated for potential future investment.

The DES model is adjusted to account for each scenario. The model alternatives are simulated to replicate 30 work days of 9 hours each. Table V presents potential savings of the proposed scenarios over the current state of the clinic. Results show the significant improvements are achievable by implementing any of the proposed scenarios. Applying scenario 3 that combines the advantages of scenarios 1 and 2 yields almost equivalent benefit to increasing the capacity of the bottleneck operation (scenario 4). Moreover, the table illustrates the impact of patient type (scheduled and walk in patients) on expected waiting time and total time of the visit. As seen in the table, walk in patients are likely to wait more than scheduled patients at the various stations of the clinic. Table VI shows a comparison 
between the results obtained from applying scenario 3 and the current state in terms of the performance of the individual work stations. Results show that the number of patients at the longest queue is noticed to drop from 10.9 (Table IV) to 7.5 patients with a slight increase in the utilization at the Resident Dr. station. In addition, the average number of served patients per work day increased by more than $13 \%$. On the down side, the increase in the number of served patients increases the utilization of the staff members of the clinic as seen in the table. Moreover, although the number of patients in the nurse station's queue largely increased in percentage, the expected number of patients in that queue is still less than one. Obtained results were presented to the quality department at the hospital for validation and pilot implementation.

Table V: Waiting time and Total visit time for the different improvement scenarios.

\begin{tabular}{|c|c|c|c|c|c|}
\hline \multirow{2}{*}{ Scenario } & \multirow{2}{*}{$\begin{array}{c}\text { Patient } \\
\text { type }\end{array}$} & \multirow{2}{*}{$\begin{array}{l}\text { Waiting time } \\
\text { (minutes) }\end{array}$} & \multirow{2}{*}{$\begin{array}{l}\text { Total visit } \\
\text { time } \\
\text { (minutes) }\end{array}$} & \multicolumn{2}{|c|}{$\begin{array}{l}\text { \% reduction in ... } \\
\text { over current state }\end{array}$} \\
\hline & & & & $\begin{array}{c}\text { Waiting } \\
\text { time }\end{array}$ & $\begin{array}{c}\text { Total visit } \\
\text { time }\end{array}$ \\
\hline \multirow{2}{*}{$\begin{array}{l}\text { Current } \\
\text { state }\end{array}$} & Scheduled & $107.92 \pm 12.71$ & $160.31 \pm 12.69$ & - & - \\
\hline & Walk in & $120.03 \pm 27.38$ & $286.49 \pm 6.93$ & - & - \\
\hline \multirow{2}{*}{ Scenario 1} & Scheduled & $80.96 \pm 9.93$ & $136.02 \pm 9.78$ & 25 & 15 \\
\hline & Walk in & $110.65 \pm 25.56$ & $307.75 \pm 8.13$ & 8 & (7) \\
\hline \multirow{2}{*}{ Scenario 2} & Scheduled & $94.72 \pm 13.28$ & $147.73 \pm 13.34$ & 12 & 8 \\
\hline & Walk in & $112.33 \pm 22.38$ & $279.40 \pm 7.93$ & 6 & 2 \\
\hline \multirow{2}{*}{ Scenario 3} & Scheduled & $76.49 \pm 7.82$ & $130.32 \pm 7.65$ & 29 & 19 \\
\hline & Walk in & $93.60 \pm 23.48$ & $294.39 \pm 8.40$ & 22 & (3) \\
\hline \multirow{2}{*}{ Scenario 4} & Scheduled & $77.04 \pm 12.438$ & $123.61 \pm 12.43$ & 29 & 23 \\
\hline & Walk in & $86.87 \pm 17.03$ & $139.88 \pm 22.74$ & 28 & 51 \\
\hline
\end{tabular}

Table VI: A comparison between Scenario 3 and current state in terms of expected waiting time in queue (minutes); expected number of patients waiting in queue; and utilization.

\begin{tabular}{|l|c|c|c|c|c|c|}
\hline \multirow{2}{*}{ Station } & \multicolumn{3}{|c|}{ Scenario 3 } & \multicolumn{3}{c|}{ \% reduction in ... over current state } \\
\cline { 2 - 7 } & $\begin{array}{c}\text { Waiting } \\
\text { time }\end{array}$ & $\begin{array}{c}\text { Number } \\
\text { waiting }\end{array}$ & Utilization & $\begin{array}{c}\text { Waiting } \\
\text { time }\end{array}$ & $\begin{array}{c}\text { Number } \\
\text { waiting }\end{array}$ & Utilization \\
\hline Clerk & $19.18 \pm 2.80$ & 2.32 & 0.42 & 16 & 13 & $(5)$ \\
\hline MR reception & $3.77 \pm 0.66$ & 0.45 & 0.45 & 38 & 36 & $(2)$ \\
\hline Nurse & $4.1 \pm 0.68$ & 0.54 & 0.38 & $(400)$ & $(440)$ & $(15)$ \\
\hline Resident Dr. & $50.57 \pm 7.36$ & 7.5 & 0.82 & 35 & 31 & $(4)$ \\
\hline Specialist Dr. & $4.41 \pm 1.00$ & 0.19 & 0.46 & 54 & 55 & 6 \\
\hline
\end{tabular}

Remark: (value) means \% of increase. 


\section{CONCLUSIONS}

The paper presents a DES study of the performance of the ophthalmology outpatient clinic of a local hospital. The study was locally supervised by the head nurse, a resident doctor and the quality supervisor. Information concerning customer complaints and work practices and procedures were obtained and validated through interviews with a medical personnel, patients and the quality department of the hospital. A survey of patients' complaints showed that waiting and lengthy visit times are key performance indicators of the system that impact satisfaction. Four improvement scenarios are tested where findings illustrated the significant reductions in waiting time and visit length attainable from implementing the proposed improvements. The proposed scenarios focused mainly on controlling the arrival pattern of patients and the operation schedule of the clinic. Results obtained from cost free scenarios were comparable to that attained from expanding the capacity at the bottleneck operation. Potential savings of up to $29 \%$ in waiting time and up to $19 \%$ in total visit length are attainable without investing in new resources. The study illustrates the usability of DES in modelling and improving the performance in healthcare services. Although results obtained from the current study may vary based on the characteristics of a system, the study approach and improvement scenarios can be generalized to improve similar healthcare systems.

\section{$\underline{\text { REFERENCES }}$}

[1] Silvester, K.; Lendon, R.; Bevan, H.; Steyn, R.; Walley, P. (2004). Reducing waiting times in the NHS: is lack of capacity the problem?, Clinician in Management, Vol. 12, No. 3, 1-5

[2] Institute for Healthcare Improvement (2005). Going lean in health care, from http://www.ihi.org, accessed on 10-11-2010

[3] Department of Veterans Affairs office of Inspector General (2010). Community Based Outpatient Clinic Reviews: Corpus Christi and New Braunfels, TX; Long Beach (Cabrillo) and Santa Fe Springs (Whittier), CA; San Diego (Mission Valley) and El Centro (Imperial Valley), CA; and Commerce (East Los Angeles) and Oxnard, CA, from http://www.va.gov/oig/54/reports/VAOIG-10-00627-208.pdf, accessed on 25-07-2010

[4] White, D. (2010). Operational planning and scheduling in the outpatient clinic environment, Dissertation, University of Cincinnati, Cincinnati

[5] Smith, A.; Barry, R.; Brubaker, C. (2007). Going Lean: Busting Barriers to Patient Flow. Health Administration Press, Chicago

[6] Hall, R.; Belson, D.; Murali, P.; Dessouky, M. (2006). Modeling patient flows through the healthcare system, Hall, R. (Ed.), Patient flow: Reducing delay in healthcare delivery, Springer, Los Angeles, 1-45

[7] Raposo, M.; Alves, H.; Duarte, P. (2009). Dimensions of service quality and satisfaction in healthcare: a patient's satisfaction index, Service Business, Vol. 3, No. 1, 85-100, doi:10.1007/ s11628-008-0055-1

[8] Al-Araidah, O.; Momani, A.; Khasawneh, M.; Momani, M. (2010). Lead-time reduction utilizing lean tools applied to healthcare: The Inpatient Pharmacy at a Local Hospital, Journal for Healthcare Quality, Vol. 32, No. 1, 59-66, doi:10.1111/j.1945-1474.2009.00065.x

[9] Jones, D.; Mitchell, A. (2006). Lean thinking for the NHS, Lean Enterprise Academy UK, from http://www.nhsconfed.org/Publications/reports/Pages/Leanthinking.aspx, accessed on 02-042010

[10] Al-Hawari, T.; Aqlan, F.; Al-Araidah, O. (2010). Performance Analysis of an Automated Production System with Queue Length Dependent Service Rates, International Journal of Simulation Modelling, Vol. 9, No. 4, 184-194, doi:10.2507/IJSIMM09(4)2.168

[11] Dhouib, K.; Gharbi, A.; Ayed, S. (2009). Simulation Based Throughput Assessment of NonHomogeneous Transfer Lines, International Journal of Simulation Modelling, Vol. 8, No. 1, 515, doi:10.2507/IJSIMM08(1)1.111 
[12] Jerbi, A.; Chtourou, H.; Maalej, A. Y. (2009). Comparing Functional and Cellular Layouts: Simulation Models, International Journal of Simulation Modelling, Vol. 8, No. 4, 215-224, doi:10.2507/IJSIMM08(4)1.147

[13] Ilar, T.; Powell, J.; Kaplan, A. (2008). Simulation of Production Lines - the Importance of Breakdown Statistics and the Effect of Machine Position, International Journal of Simulation Modelling, Vol. 7, No. 4, 176-185, doi:10.2507/IJSIMM07(4)2.105

[14] Werker, G.; Saure, A.; French, J.; Shechter, S. (2009). The use of discrete-event simulation modelling to improve radiation therapy planning processes, Radiotherapy and Oncology, Vol. 92, No. 1, 76-82, doi:10.1016/j.radonc.2009.03.012

[15] Oh, H. C.; Chow, W. L. (2011). Scientific Evaluation of Polyclinic Operating Strategies with Discrete-Event Simulation, International Journal of Simulation Modelling, Vol. 10, No. 4, 165176, doi:10.2507/IJSIMM10(4)1.178

[16] Mandahawi, N.; Al-Shihabi, S.; Abdallah, A.; Alfarah, Y. (2010). Reducing waiting time at an emergency department using design for Six Sigma and discrete event simulation, International Journal of Six Sigma and Competitive Advantage, Vol. 6, No. 1-2, 91-104, doi:10.1504/ IJSSCA.2010.034858

[17] Martin, M.; Champion, R.; Kinsman, L.; Masman, K. (2010). Mapping patient flow in a regional Australian emergency department: A model driven approach, International Emergency Nursing, Vol. 19, No. 2: 75-85, doi: 10.1016/j.ienj.2010.03.003

[18] Sizmur, S.; Redding, D. (2010). Key domains of the experience of hospital outpatients, from http://www.pickereurope.org/Filestore/Policy/position_papers/Discussion_paper_2_core_domai ns_outpatient_experience_June_2010.pdf, accessed on 05-06-2011

[19] Kelton, W. D.; Sadowski, R. P.; Sadowski, D. A. (2002). Simulation with Arena, McGraw-Hill, New York

[20] Rockwell Automation (2010). Arena Simulation Software, Version 12.0, Help, from http://www.arenasimulation.com/, accessed on 26-04-2011

[21] Marvel, J. H.; Standridge, C. R. (2009). A simulation-enhanced lean design process, Journal of Industrial Engineering and Management, Vol. 2, No. 1, 90-113, doi:10.3926/jiem.2009. v2n1.p90-113

[22] Alexopoulos, C.; Goldsman, D.; Fontanesi, J.; Kopald, D.; Wilson, J. (2008). Modeling patient arrivals in community clinics, Omega, Vol. 36, No. 1, 33-43, doi:10.1016/j.omega.2005.07.013

[23] Montgomery, D. C. (2001). Design and analysis of experiments, John Wiley \& Sons, New York 